\title{
Detección de antígenos dominantes para el diagnóstico de cisticercosis por inmunoelectrotransferencia (Eitb)
}

\author{
Gladys Pinilla 1*, Jeannette Navarrete 1, Carmen C. Almonacid ， \\ Martha Bermudez ${ }^{1}$ y Luis Carlos Villamil ${ }^{2}$. \\ ${ }^{1}$ Programa de Bacteriología, Facultad de Ciencias de la Salud, Universidad Colegio Mayor de Cundinamarca. Bogotá, Colombia. \\ ${ }^{2}$ Programa de Posgrado en Salud y Reproducción Animal, Facultad de Medicina Veterinaria y Zootecnia de la Universidad \\ Nacional de Colombia. Bogotá, Colombia \\ Recibido: 23-07-03; Aceptado:05-09-03
}

\begin{abstract}
RESUMEN
Se emplearon quistes liofilizados de Cisticerco cellullosae para preparar un extracto antigénico, el cual se utilizó en la identificación de antígenos de Taenia soliumreconocidos por inmunoglobulinas G de pacientes con cisticercosis, por medio de la prueba de inmunoelectrotransferencia (EITB). Se estudiaron 193 muestras (105 líquidos cefalorraquídeos - LCR y 88 sueros) de individuos con diagnóstico de cisticercosis por hallazgos clínicos, epidemiológicos y serológicos mediante el inmunoensayo enzimático (ELISA). El análisis de las proteínas antigénicas por electroforesis, permitió identificar polipéptidos de 29, 45, 66, 96 y 116 kDa principalmente, así como también algunos menores de $29 \mathrm{kDa}$. Los de mayor frecuencia de aparición en muestras de suero y LCR fueron los de 29, 45 y $66 \mathrm{kDa}$. Por lo tanto, estos antígenos inmunodominantes, podrían emplearse con predilección en estudios epidemiológicos y clínicos de cisticercosis por western blot

Palabras Claves : Cisticercosis, ELISA, inmunidiagnóstico, EITB.
\end{abstract}

\begin{abstract}
Detection of dominants antigens to diagnosis of cisticercosis for immunoelectrotransference (EITB)

It is employed lyophilized cyst of Cisticerco cellulosae to prepare antigenic extract of which it is used in the identification of Taenia solliumantigens recognized for $\mathrm{IgG}$ antibodies of patients with cisticercosis, for immunoelectrotransfer assay (EITB). It is analyze 193 samples (105 cerebrospinal fluid and 88 sera) from patients with diagnosis of cisticercosis for finding clinic, epidemiologic and inmunienzimatic assay (ELISA). The analysis of the antigenic proteins for electrofiretic, allowed to identify polypeptides of 29, 45, 66, 96 and $116 \mathrm{kDa}$. The frecuency greates in sera and LCR was 29, 45 and $66 \mathrm{kDa}$. In conclusion, this immunidominants, will power employ in epidemiologic studies and cisticercosis clinics for Western blot.
\end{abstract}

Key words : Cisticercosis, ELISA, immunidiagnosis, EIBT.

* Correspondencia: Gladys Pinilla, e-mail: gpbmt@yahoo.com 


\section{Iintroducción}

La cisticercosis es una zoonosis producida por la larva (Cisticerco cellulosae) del céstodo Taenia solium, en la cual el hombre se comporta como huésped definitivo mientras que el cerdo lo hace como intermediario. El parásito se adquiere (tanto en el ser humano como en el animal) a través de alimentos y agua contaminada con heces infectadas, a su vez, con huevos de Taenia solium,situación que se facilita en los cerdos por sus hábitos coprofágicos.

El ser humano desarrolla teniasis por ingestión de cisticercos en carne de cerdo insuficientemente cocida $\mathrm{y}$, al actuar como portador, puede permanecer infectado por varios años sin presentar manifestaciones clínicas al tiempo que representa una fuente potencial de contagio, ya que expulsa 300.000 huevecillos diarios, la mayoría de ellos con capacidad de infectar (1). Los cisticercos pueden asentarse en cualquier tejido del organismo humano, pero generalmente lo hacen en los músculos, la grasa subcutánea, los ojos o en el sistema nervioso central (SNC), el encéfalo y las envolturas meníngeas, como es el caso de la neurocisticercosis, que frecuentemente causa discapacidad física y en ocasiones la muerte. La investigación médica que permite el conocimiento básico de la patología y sus agentes, el reciente desarrollo de vacunas para el cerdo, al igual que el mejoramiento diagnóstico en cuanto a sensibilidad y especificidad, entre otros, son factores primordiales para prevenir y controlar la enfermedad (2).

El diagnóstico de la cisticercosis se basa en hallazgos clínicos, epidemiológicos, pruebas serológicas y estudio de imágenes radiológicas. Para identificar a los portadores del parásito adulto Taenia solium, se realiza un diagnóstico convencional por microscopia; también se utilizan pruebas con coproantígenos, que proporcionan mayores niveles de sensibilidad (3). Por otra parte, se han probado técnicas de diagnóstico molecular de teniasis con secuencias de ADN complementario (ADNc) de T. solium, e hibridización para la detección de huevos en heces $(4,5)$; además se estableció el uso de la reacción en cadena de la polimerasa (PCR) en el diagnóstico de especies de T. saginata y $T$. solium, para identificar posibles variaciones genéticas (6).

Las principales pruebas serológicas en el diagnóstico de la cisticercosis son el ensayo inmunoenzimático (ELISA), la inmunoelectrotransferencia (EITB) o Western blot que detectan anticuerpos en muestras de suero y líquido cefalorraquídeo y constituyen una ayuda importante para los profesionales de la salud (7-10).

En este trabajo se presenta la metodología empleada para la realización de inmunoelectrotransferencia (EITB) en muestras de humanos afectados por la enfermedad, así como también la identificación de antígenos inmunodominantes para ser utilizados en procedimientos de Western blot.

\section{Materiales y métodos}

Población en estudio y muestras clínicas: Se analizaron 193 muestras de las cuales 88 correspondieron a sueros y 105 a LCR de pacientes provenientes de zonas endémicas de Colombia (Bogotá, Nariño, Atlántico, Tolima, Caldas y Tunja); con diagnóstico de cisticercosis por ELISA, los cuales fueron suministrados por la Red del Grupo de Parasitología del Instituto Nacional de Salud (INS). Como grupos controles se utilizaron sueros y LCR de personas sin afecciones neurológicas, de pacientes infectados con otras parasitosis y de individuos con otras neuropatologías diferentes a neurocisticercosis.

Extracto Antigénico: Como extractos antigénicos se emplearon quistes liofilizados de Cisticerco cellulosae, los cuales fueron proporcionados por el Programa de Postgrado en Salud y Producción Animal de la Facultad de Medicina Veterinaria y Zootecnia de la Universidad Nacional de Colombia. Se realizó la homogenización y extracción de lípidos con solventes orgánicos (éter-acetona 1:1) en presencia de inhibidores de proteasas (PMSF 25mM); se sometió a procesos de fraccionamiento por medio de sonicación (tres pulsos 
de $40 \mathrm{~Hz}$ por tres minutos con espacio de $60 \mathrm{seg}$. a $4^{\circ} \mathrm{C}$ ) y, por último, se centrifugó a $25.000 \mathrm{rpm}$. por 30 min. a $4^{\circ} \mathrm{C}$. La cuantificación de proteínas se realizó por el método de Bradford (11); el antígeno así obtenido se almacenó a $-40^{\circ} \mathrm{C}$. Se obtuvo una concentración de proteínas de $4.5 \mathrm{mg} / \mathrm{ml}$ como promedio.

Electroforesis PAGE-SDS: Los geles preparados fueron cargados con el extracto antigénico a una concentración de $0.9 \mathrm{mg} / \mathrm{ml}$. Se realizó tinción con Azul de Coomassie en sus variantes lenta (R250) y rápida (G250); en ésta última coloración, el gel se fijó en solución de metanol $10 \%$ y ácido acético $7 \%$ por 20 min.; se sumergió en el colorante (Azul de Coomassie G250 al 0.1\% en ácido peryódico al 3.5\%) por $20 \mathrm{~min}$. Para visualizar las proteínas, se decoloró el gel con solución de metanol-ácido acético por 30 a 60 min. (12, 13) (Figura 1).

Inmunoelectrotransferencia (EITB): El antígeno fue transferido a membranas de nitrocelulosa (20 Voltios, 18 horas, $4^{\circ} \mathrm{C}$ ). Para la inmunodetección, las tiras de papel se bloquearon en Buffer Tris Salino-Tween (TTBS) al $0.05 \%$, leche descremada al 5\%, por 24 horas a $-4^{\circ} \mathrm{C}$. Las tiras se incubaron por una hora en agitación continua a temperatura ambiente con los sueros y LCR en dilución de $1 / 50$ y $1 / 5$ respectivamente en TTBS-leche. Se utilizaron dos tipos de revelado enzimático: el sistema Proteína G marcada con peroxidasa y el sistema de amplificación de señal estreptavidina-fosfatasa alcalina.

\section{Resultados}

Electroforesis PAGE-SDS: El peso molecular de los polipéptidos del antígeno correspondieron a 24, 29 , 36, 40, 45, 60, 66, 70, 96, 103, 116, 120, 132, 136 y 139 kDa. El método de tinción con Azul de Coomassie en su variante rápida (G250) fue el más apropiado, por rapidez y costo, además permitió la detección de las mismas bandas que se detectan con la coloración tradicional R250 (14) (Figura 1).

www.unicolmayor.edu.co
Electroinmunotransferencia (EITB): Las proteínas inmunógenas de más frecuente aparición en el Western blot fueron las de 29, 45 y $66 \mathrm{kDa}$, tanto en suero como en LCR (Figura 2). Estos péptidos inmunodominantes presentaron una frecuencia de $41 \%$, $94 \%$ y $65 \%$ respectivamente, en muestras de suero y $21 \%, 27 \%$ y $19 \%$ respectivamente en muestras de LCR. De las muestras negativas por ELISA y positivas por EITB se evidenció que el antígeno reconocido con mayor frecuencia fue el de $29 \mathrm{kDa}$.

El EITB, en este estudio, presentó una sensibilidad de $79 \%$ y una especificidad del $89 \%$ en muestras de suero; y sensibilidad de $85 \%$ y especificidad del $100 \%$ en muestras de LCR.

No se observaron reacciones positivas al utilizar muestras de individuos sanos y muestras de pacientes con otras parasitosis; tampoco se obtuvo reacción con sueros y LCR de pacientes con diversas neuropatologías diferentes a neurocisticercosis.

\section{Discusión}

En la preparación del antígeno somático de Cisticerco cellullosae se eliminó una cantidad considerable de lípidos, lo cual se constituía en uno de los problemas que se abordarían, debido a que este parásito presenta en su estructura vesículas almacenadoras de lípidos (15) que pueden interferir en los ensayos que se realicen. Es importante anotar que se evidenció un patrón de bandeo diferente en algunos lotes de antígeno, lo que se puede asociar a su grado de pureza.

En cuanto al método de tinción de proteínas, el empleo de Azul de Coomassie G250, correspondiente a la variedad de tinción rápida, es una alternativa de elección para revelar las bandas proteicas fácil y rápidamente, ya que se evidencian los mismos resultados que con el método tradicional R250 (tinción lenta), presentando ventajas de ahorro en tiempo y costo.

Para los métodos de revelado utilizados en la prueba de Western blot se recomienda el uso de la 


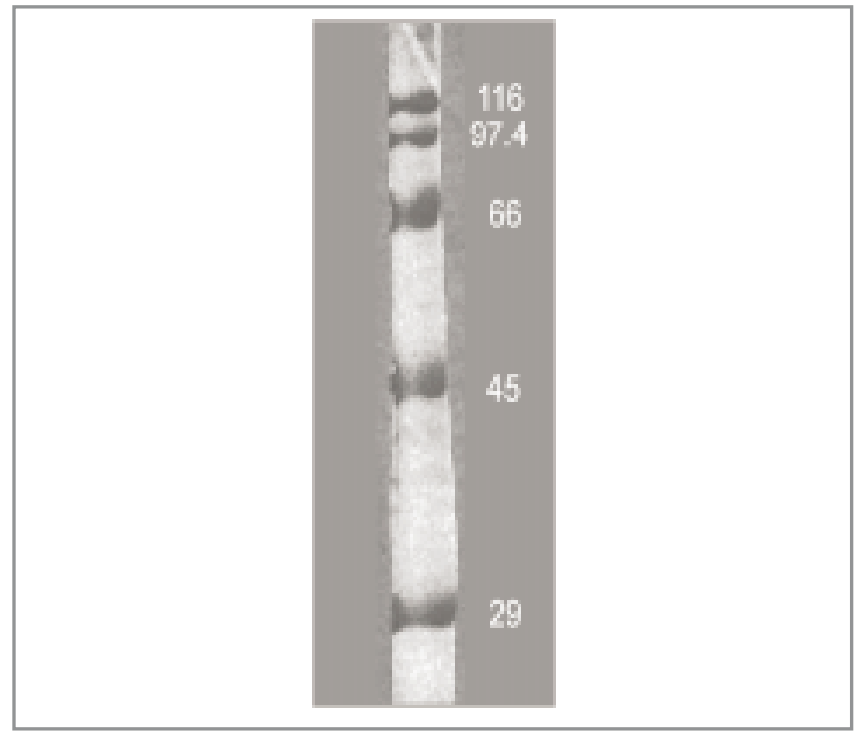

Figura 1 . Electroforesis PAGE-SDS del antígeno de solium. Patrón de bandas obtenidas.

Taenia

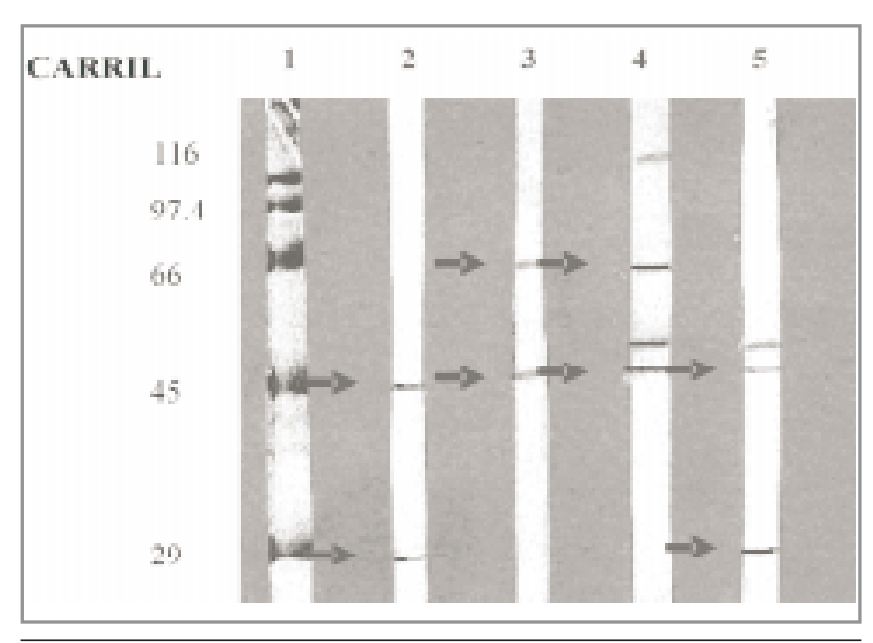

Figura 2. INMUNOELECTROTRANSFERENCIA(EITB) DEANTÍGENOS INMUNODOMINANTES DE TAENIA SOLIUM -Identificación de polipéptidos reconocidos por inmunoglobulina $\mathrm{G}$ en suero y líquido cefalorraquídeo de pacientes con cisticercosis. Se reconocen los antígenos de 29, 45 y $66 \mathrm{kDa}$ como polipéptidos inmunodominantes. Carril 1: Patrón de peso molecular. Carri 12 y 3: muestras de suero Carril 4 y 5: muestras de LCR. Carri 16 : Control negativo. (14) .

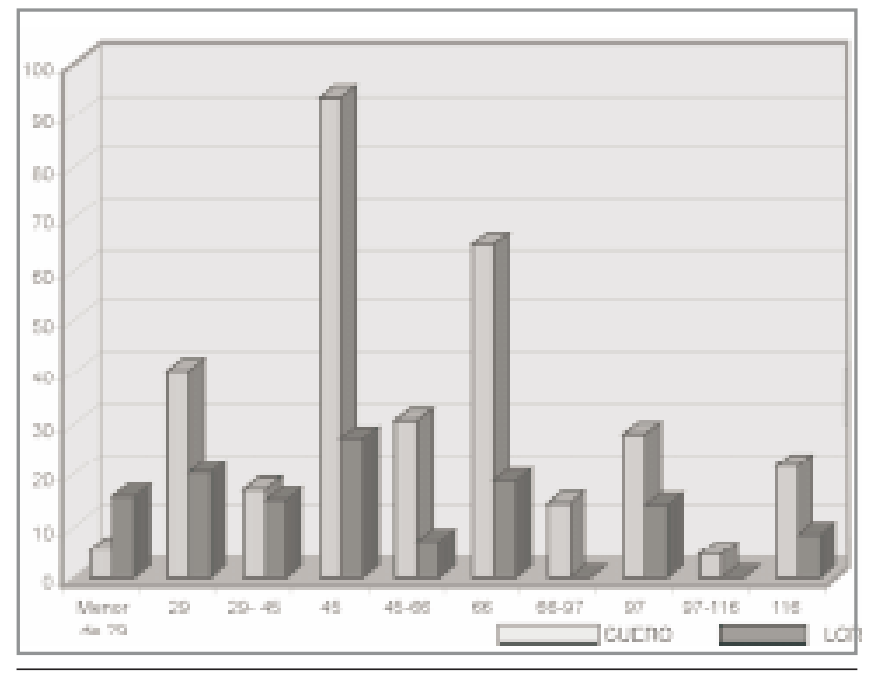

Figura 3. FRECUENCIA DE POLIPÉPTIDOS INMUNODOMINANTES EN LA DETECCIÓN DE NEUROCISTICERCOSIS POR EITB PESO MOLECULAR (kDa). Análisis de la frecuencia de polipéptidos inmunógenos que reaccionaron con las muestras de sueros y LCR de pacientes con diagnóstico serológico de cisticercosis. Las frecuencias más altas corresponden a las proteínas de 29, 45 y 66 $\mathrm{kDa}$ tanto en suero como en LCR.

inmunodominantes, tanto en muestras de suero como en LCR, correspondieron al peso molecular de 29, 45 y $66 \mathrm{kDa}$ (Figura 2); de igual manera, se encontró que hay mayor frecuencia de reconocimiento de estos polipéptidos por los anticuerpos en muestras de suero, comparados con los reconocidos en LCR. Por var tres bandas simultáneas como número promedio, reconocidas muestras de suero y LCR; los antígenos 
consiguiente, estas proteínas inmunógenas son las que se recomiendan, en este estudio, para tenerse en cuenta en la detección de cisticercosis por EITB.

El polipéptido de $29 \mathrm{kDa}$ fue reconocido por el 1\% de las muestras negativas por ELISA, pero positivas por EITB, el cual probablemente es un polipéptido que se presenta en un estadio específico de la enfermedad y requiere otro tipo de análisis $(10,16)$. Es de destacar que el polipéptido de $45 \mathrm{kDa}$ es el más reconocido, presentando una frecuencia de $94 \%$ en las muestras de suero y de $27 \%$, en las muestras de LCR (Figura 3). La reactividad antigénica de esta fracción proteica ha sido valorada tanto con sueros humanos como de cerdos, por lo que se sugiere su utilización en la estandarización de pruebas diagnósticas de campo para estudios epidemiológicos de la cisticercosis porcina y humana (19).

Por otro lado, se probó la especificidad del ensayo utilizando sueros y LCR positivos para otras parasitosis y de pacientes con otras neuropatologías del sistema nervioso central, lo mismo que con muestras de individuos sanos y no se evidenciaron reacciones cruzadas.

La evaluación de la prueba Western bloț determinó una sensibilidad de $79 \%$ y una especificidad de $89 \%$ en muestras de suero; $y$ en muestras de LCR una sensibilidad de $85 \%$ con una especifidad del $100 \%$, lo que corrobora su utilidad y amplia aceptación como herramienta diagnóstica de gran utilidad para estudios de tipo clínico y epidemiológico.

La cisticercosis es una enfermedad que puede ser prevenida y probablemente erradicada en nuestro medio, con la aplicación de programas de control y vigilancia epidemiológica, los cuales incluyen mejoramiento de condiciones sanitarias, educación en salud y el diagnóstico certero y oportuno en áreas endémicas.

\section{Referencias}

1. Sarti E. La teniosis y cisticercosis por Taenia solium. Revista de Salud Pública de México 1998; 39(3):1-13.

2. Pinilla G, Navarrete J, Almonacid C, Bermúdez M. Cisticercosis: zoonosis y sociedad; aspectos inmunológicos, de diagnóstico y control. Impreso universitario. Bogotá: Facultad de Cien- cias de la Salud, Universidad Colegio Mayor de Cundinamarca; 2003.

3. Allan JC, Velásquez M, Torres R, et al. Field trial of diagnosis of Taenia solium taeniasis by coproantigen enzyme linked inmunosorbent assay. Am J Trop Med Hyg 1996;54:352-6.

4. Chapman A, Vallejo V, Mossie KG, et al. A. Isolation and characterization of species-specific DNA probes from Taenia soliumandTaenia saginata and their use in egg detection assay. J Clin Microbiol 1995;33(5):1283-8.

5. Pinilla G, Navarrete J, Serrano ML. Generaciones diagnósticas en cisticercosis: del microscopio a la biología molecular. Acovez 1998;23(2):20-4.

6. González LM. PCR tool for the differential diagnosis of Taenia saginataandTaenia soliumtaeniasis / cisticercosis from different geographical locations. Diagn Microbiol Infect Dis 2002;2 (4):243-9.

7. Feldman M, Plancarte A, Sandoval M, et al. Comparison of two assays (EIA and EITB) and two samples (saliva and serum) for the diagnosis of neurocysticercosis. Trans Roy Soc Trop Med Hyg 1990;84:559-62.

8. Sloan L, Schneider S, Rosenblatt J. Evaluation of enzyme-linked immnunoassay for serological diagnosis of cysticercosis. J of Clin Micro 1995;33:3124-8

9. Garcia H, Harrison LJ, Parkhouse RM, et al. A specific antigendetection ELISA for the diagnosis of human neurocysticercosis. The cysticercosis working group in Peru. Trans Soc Trop Med Hyg 1998;92(4):411-4.

10. Winograd E, Rojas A. Identification of two nonglycosylated polypetides of Taenia solium recognized by immunoglobulins from patients with neurocysticercosis. Parasitol Res 1999;85:513-7.

11. Bradford M. A rapid and sensitive method for the quantitation of microgram quantities of protein utilizing the principle of protein- die binding. Anal Biochem 1976;72:248-54.

12. Laemmly YU. Cleavage of structural proteins during assembly of the head of bacteriophage T4. Nature 1970;227:680-5.

13. Maniatis F, Sambrok J. Molecular Cloning Manual Laboratory. $2^{\mathrm{a}}$ ed. New York: Col Spring Harbor Laboratory Press; 1989.

14. Pinilla G, Navarrete J, Almonacid C, Bermúdez M. Análisis de métodos de revelado para electroforesis PAGE-SDS y western blot en el diagnóstico de cisticercosis. Bogotá: Universidad Colegio Mayor de Cundinamarca, Facultad de Ciencias de la Salud, Programa de Bacteriología; 1999.

15. Flisser A, Williams K, Laclette JP, et al. Biochemical and immunologycal characterization of antigen B purified from cysticerci of Taenia solium In: Cysticercosis: Present state of knowledge and perspectives. New York: Academic Press; 1982. p. 437-51.

16. Tsang, V, Brand J, Boyer A. An Enzyme linked immonuelectrotransfer bot assay and glicoprotein antigens for diagnosis human cysticercosis (Taenia solium). J Infect Dis 1989;159(1):50-9.

17. Ev LV, Maia AA, Pianetti G, Nascimento N. Immunologycal evaluation of $26 \mathrm{kDa}$ antigen from Taenia solium larvae for especific immunodiagnosis of human neurocysticercosis. Parasitol Res 1999;85(2):98-102.

18. Flisser A, Plancarte A, Correa D, et al. New approaches in the diagnosis of Taenia solium cysticercosis and taeniasis. Ann Parasitol Hum Comp 1990;65(Suppl 1):95-8.

19. Giraldo JC, Piragauta MA, Vargas C, et al. Valoración de la reactividad antigénica con sueros de porcino de las fracciones de 95, 45 y $36 \mathrm{kDa}$. del metacéstodo de Taenia solium Revista Científica de UNIINCA 2001;7(1):23-33. 